Psychiatric Bulletin (2000), 24, 201-202

\title{
JOHN COX
}

\section{Person-power}

\section{Reflections on the mental health National Service Framework for adults of working age}

The recent publication by the Department of Health of the long-awaited, much-trumpeted, National Service Framework (Department of Health, 1999) for 'adults of working age' should be widely discussed throughout the College. It will undoubtedly influence the direction of mental health services in England, probably for the next decade.

The National Service Framework for Mental Health (NSF-MH) has already triggered several memorable comments such as "Oh I thought it was a National Schizophrenia Framework" or "Isn't a vision without resources a hallucination?" Nevertheless, these quick and humorous reactions, even if motherhood and apple pie are also not the flavour of the month, are probably wide of the mark. The NSF-MH is a comprehensive integrative vision of a modern mental health service which brings together social and health services, carers and consultants, primary and secondary care, psychological and pharmacological treatments and is based as far as possible on 'evidence'. As such, it will repay careful scrutiny and a considered response from the College to the several questions raised. For example, what are the pros and cons of psychiatric services being placed within primary care or specialist mental health trusts?

Can this Utopian vision, which includes something for everybody, be delivered in 5-10 years? It is recognised that the answer to this question is contingent on recruiting and retaining the mental health workforce and in particular on the availability of adequate human and financial resources. There is to be an Implementation and Workforce Planning Group which will have to face these hard realities in the short term - and yet sustain the vision of a longer term improvement of services.

Sadly, at present there are persistent major manpower constraints which, until reduced in a convincing manner, will prevent the achievement of these standards: realising the vision could, therefore, be a 'pipe dream', with the risk that the framework will be just that - a framework - a scaffold without bricks and mortar. It is apparent that government ministers and civil servants are determined that this will not happen and rightly are seeking the help of professional bodies and user groups.

The NSF-MH is concerned specifically with the mental health of adults of working age and is a challenge to adult psychiatrists in particular. Its success is partially contingent on this large group of consultants $(n=1368)$ rediscovering and retaining their specific range of knowledge, attitudes and skills, and so becoming stronger advocates for their speciality. However, the percentage of vacant consultant posts in general adult psychiatry remains at $14.5 \%$ - twice the rate of vacancies in Scotland. Trainees are often denied strong role models to overcome their concern about a work environment regarded as inferior to that of other specialities. Acute psychiatric units have even been described as 'nontherapeutic' by both the nurses in their recent report to the Department of Health, and in the survey carried out by the Sainsbury Centre for Mental Health.

In an unpublished survey by Mary Ryan, Mariam Hanna and myself (further details available from the author upon request), we endeavoured to determine the reasons why trainees who passed MRCPsych Part I did not continue to take Part II, and so 'dropped out'. We found that of the 206 doctors who replied (57\% response rate) only $24 \%$ were still in an approved training rotation; 31 were in a staff grade post and 24 had left the NHS altogether. Eighty-six (42\%) trainees had already decided not to have a further attempt at Part II, and 31 were uncertain whether or not they would do so. The most commonly cited reason for moving from an approved training post or leaving psychiatry were the stress of being responsible for patients $(n=15)$ lack of supervision/support from the consultant or tutor $(n=15)$ and concern about the workload of consultant posts $(n=13)$.

In 1996, consultants were also leaving the NHS, and an additional survey of 321 college tutors estimated the number of local vacant consultant posts and the 'best guesses' as to why consultants were leaving. This survey showed that a quarter of consultants left for 'personal' reasons, $23 \%$ to improve their career and $7 \%$ moved to private practice. 
Since this postal survey recruitment into psychiatry has increased substantially and there is evidence of increased competition for consultant posts. Nevertheless, until we recruit and retain trainees and consultants in a more sustained manner delivering the NSF-MH will be unrealistic. Unused national training numbers (over 100), must be quickly found and filled so that the promise of an increased number of specialist registrars and of consultant expansion (which is on offer) can be realised.

Certainly, the General Adult and Community Psychiatry Faculty of the College faces a substantial challenge, but so do other Faculties, such as the Old Age Faculty, who have a similar percentage of unfilled posts. Until the services for adult mental illness are improved and the quality of life on admission wards approaches minimum standards the quality of other services will be adversely affected. There is, therefore, a need for general psychiatrists to show how it is sometimes possible to swim in choppy water, to enable a multi-disciplinary team to flourish and to attempt to deliver a comprehensive service. There is a need to restore, if possible, the heart to this once pristine speciality.

There is also a need for bold and novel incentives from government to attract and retain doctors in the acute services which are at the core of a secondary care service and central to the success of the NSF-MH. The inclusion of standards for users and carers is not just fashionable, but fundamentally central to a modern health service in a post-modern society. These groups can be our greatest allies.

Although it is the responsibility of leaders to lead and a part of leadership is to show vision - 'without vision the people die', to mix visionary idealism with realism is also crucial for credibility. There is a real need for more adult psychiatrists 'on the ground', and for more contented foot soldiers provided with the right equipment and appropriate rewards. There is certainly a need for more manpower: the government should give a bold and imaginative lead in the context of the review of NHS manpower presently being undertaken.

It is 'people-power' that will determine whether the 'framework' remains only as a scaffold without bricks or mortar or as a skeleton of only dry bones with no life.

There is, at last, the beginning of a consensus about the overall direction of mental health services which is much to be welcomed. What is now required are adequate resources and a period of consistent policymaking.

\section{Reference}

DEPARTMENT OF HEALTH (1999)

National Service Framework for Menta

Health. London: Department of Health.

John Cox President, Royal College of Psychiatrists, 17 Belgrave Square, London SW1X 8PG 